\title{
Evaluation of the Penn Macy initiative to advance academic nursing practice
}

Lois K. Evans DNSc, RN, FAAN

University of Pennsylvania

Beth Ann Swan PhD, CRNP

Thomas Jefferson University

Norma E. Lang PhD, RN, FAAN, FRCN

University of Pennsylvania

Follow this and additional works at: https://jdc.jefferson.edu/nursfp

Part of the Nursing Commons

Let us know how access to this document benefits you

\section{Recommended Citation}

Evans, Lois K. DNSc, RN, FAAN; Swan, Beth Ann PhD, CRNP; and Lang, Norma E. PhD, RN, FAAN, FRCN, "Evaluation of the Penn Macy initiative to advance academic nursing practice" (2003). College of Nursing Faculty Papers \& Presentations. Paper 9.

https://jdc.jefferson.edu/nursfp/9

This Article is brought to you for free and open access by the Jefferson Digital Commons. The Jefferson Digital Commons is a service of Thomas Jefferson University's Center for Teaching and Learning (CTL). The Commons is a showcase for Jefferson books and journals, peer-reviewed scholarly publications, unique historical collections from the University archives, and teaching tools. The Jefferson Digital Commons allows researchers and interested readers anywhere in the world to learn about and keep up to date with Jefferson scholarship. This article has been accepted for inclusion in College of Nursing Faculty Papers \& Presentations by an authorized administrator of the Jefferson Digital Commons. For more information, please contact: JeffersonDigitalCommons@jefferson.edu. 


\title{
Evaluation of the Penn Macy Initiative to Advance Academic Nursing Practice
}

\author{
Lois K. Evans, DNS , RN, FAAN, * Beth Ann Swan, PhD, CRNP, \\ and Norma E. Lang, PhD, RN, FAAN, FRCN ${ }^{\ddagger}$ \\ *Viola MacInnes/Independence Professor, School of Nursing, University of Pennsylvania, Philadelphia, PA. \\ ${ }^{+}$Adjunct Assistant Professor, Special Projects Coordinator,Penn Nursing Network, and Post Doctoral \\ Research Fellow, Robert Wood Johnson Foundation/Campbell Collaboration, Philadelphia, PA. \\ ${ }^{\ddagger}$ Lillian S. Brunner Professor of Nursing, School of Nursing, University of Pennsylvania, Philadelphia, PA.
}

Supported by the Josiah Macy, Jr. Foundation of New York in underwriting the Penn Macy Initiative in its initial planning and implementation.

Address correspondence and reprint requests to Dr. Evans:

School of Nursing, University of Pennsylvania,

420 Guardian Drive, Philadelphia, PA 19104-6096.

E-mail: evans@nursing.upenn.edu

\begin{abstract}
In the realm of academic practice, schools of nursing, especially those in research-intensive environments, face a dilemma. These schools are in the best position to shape nursing science through research based in academic practice. Yet they also face formidable challenges to maintaining balance among the three legs of the tripartite mission. The questions of whether and how to commit resources to move forward their academic practice agendas are not answered easily. The Penn Macy Initiative to Advance Academic Nursing Practice aimed to assist such schools in their development of academic practices through a week-long intensive institute and 1 year of consultation and follow-up. An evaluation of the outcomes of that experience for 21 participant schools together with the baseline characteristics that appeared, retrospectively, to be associated with success are presented and discussed.
\end{abstract}

Academic nursing practice is the "intentional integration of research, education, and clinical care in an academic setting for the purposes of advancing the science and shaping the structure and quality of health care" (Lang, Evans, \& Swan, 2002, p.63). Schools of nursing in research-intensive environments have the greatest potential for making such contributions. Yet they face formidable challenges in integrating and balancing the tripartite mission. Over a 2-year period, with support from The Josiah Macy, Jr. Foundation of New York, the University of Pennsylvania School of Nursing provided a structured forum for assisting and supporting a critical mass of 21 participant schools in meeting these challenges.

The Penn Macy Initiative to Advance Academic Nursing Practice consisted of a comprehensive institute and consultative technical assistance program to help schools of 
nursing create and advance academic practice. Applications were solicited from schools in research-intensive environments (located in Carnegie Research I or II universities, and/or having a doctoral program in nursing, and/or being top ranked in National Institutes of Health research funding). Ten schools in year 1 and 11 in year 2 were selected to participate. For the week-long summer institute, each school created and sent a team of up to 3 people who represented the strategic perspectives of research/practice nursing faculty, health care business management or equivalent, and/or academic financial administration. During the Institute, schools refined their own 12-month goals regarding advancing academic practice. In the ensuing year, each school was eligible to receive up to 5 hours of individualized consultation on any topic related to meeting their academic practice goals. A Web site, monthly chat room, listserv, and 2 follow-up meetings provided additional opportunities for participants to consult and problem solve with their peers and experts. Details of the content and structure of the initiative are described elsewhere (Lang et al., 2002).

The purposes of this article are to describe the evaluation methodology and process used to determine the effectiveness of the Initiative and to discuss participant outcomes after the first year. Characteristics of the participating schools as well as the learning and evaluation processes used are described first, followed by detailed findings from 2 types of evaluation: participant feedback and structured self-report. The relationships between the schools' baseline characteristics and their progress in goal achievement are analyzed and discussed. Finally, key indicators of readiness for progress are suggested to guide schools of nursing contemplating launching their own integrated academic practice journeys.

\section{Description of Participant Schools}

\section{APPLICATION PROCESS}

In soliciting applications for the Penn Macy Initiative (PMI), information regarding a range of school attributes, characteristics, and experiences was sought. Recognizing that each prospective participant school would bring its own unique set of strengths, the PMI faculty believed that schools at similar levels of readiness to mount the next steps in their academic practice trajectory would best learn together. Such composition also would enable the faculty to structure the types of information and learning experiences at a common level for the week-long Institute. Thus, as part of the application process, the schools were asked to present a self-assessment of their own strengths and goals regarding academic practice. The application form itself was refined for year 2 to further clarify the types of information sought. In each year, the following categories of information were obtained from each applicant school:

- Description of interest in academic nursing practice development;

- Long-range/strategic plan or philosophy/mission/vision pertaining to academic practice;

- History in developing academic nursing practice;

- Expertise in business, finance, and reimbursement for practice; 
- Strengths for achieving academic practice goals;

- Analysis of barriers to implementing academic practice;

- Specific objectives for participating in the Penn Macy Initiative;

- Placement of academic practice in the table of organization;

- Funding experience in support of academic practice (research, program grants) for the past 5 years;

- Description of current practices;

- Appointment/promotion/tenure policies pertinent to academic practice.

Schools' own descriptions of these areas on the application formed the basis for competitive selection of participants for the PMI and also provided baseline data for the evaluation. No attempt was made to verify these data beyond that provided on the application. The participant schools are named in Table 1.

\section{TABLE 1. Penn Macy Initiative Participating Schools}

\begin{tabular}{ll}
\hline \multicolumn{1}{c}{1999} & \multicolumn{1}{c}{2000} \\
\hline New York University & Pennsylvania State University \\
Temple University & Rutgers University \\
University of California at Los Angeles & University of Florida \\
University of Colorado & University of Iowa \\
University of Kentucky & University of Michigan \\
University of Rochester & University of Minnesota \\
University of Texas & University of Nebraska \\
University of Virginia & Vanderbilt University \\
University of Washington & Virginia Commonwealth University \\
University of Wisconsin-Madison & Wayne State University \\
& West Virginia University
\end{tabular}

NOTE. $\mathrm{N}=21$

\section{PARTICIPANT SCHOOL CHARACTERISTICS}

Of the 21 schools selected, the majority (18) were in large public universities (Table 2). Their history of practice experience differed greatly. Three schools reported very early (1970s and earlier) experience with organizational integration (e.g., unification models); 9 had experimented with nursing centers or faculty practices beginning in the 1980s, whereas the remaining 9 described a more recent experience with practice or faculty practice plan development. Schools with a long history of graduate programs for advanced practice were more likely also to have had longer experience with structured faculty practice.

Organizational support for the practice component of the tripartite mission was measured by inclusion of practice in the school's statements of mission/vision/philosophy, 
the integral role given to practice in the school's strategic plan, and presence of a named practice leadership position on the school's organizational chart. Three fourths of the participating schools' mission, vision, and/or philosophy statements included practice, and of these nearly one-third referred only to service. This was particularly true for those in land grant public universities. Slightly more (86 percent) of the schools' long-range strategic plans included academic practice as an integral component. All but 3 of the participating schools listed a position or office related to practice on the organizational chart; many of these were at the level of an associate dean, and all but 3 had a direct reporting line to the dean.

\section{TABLE 2. Baseline Characteristics of Participating Schools}

\begin{tabular}{ll}
\hline \multicolumn{1}{c}{ Characteristic } & Participant Summary Description \\
\hline Parent institution & $18(86 \%)$ \\
Public (n/\%) & $3(14 \%)$ \\
Private (n/\%) & X 12.7 y, median, 11 y, range, 2-26 y \\
Academic nursing practice experience (y) & $18(86 \%)$ \\
Practice is integral to long range plan (n/\% yes) & $16(76 \%) ; 5$ of these specify service only \\
Practice is included in mission/vision/philosophy (n/\% yes) & $18(86 \%)$ \\
Practice appears on organizational chart (n/\% yes) & $17(81 \%)$ \\
Practice activity includes financial risk taking for school (n/\% yes) & $16(76 \%)$ \\
Practice portfolio represents mixed model (n/\% yes) & $12(57 \%)$ \\
Application identified practice business expertise (n/\% yes) & $11(52 \%)$ \\
Fac practice plan is in place (n/\% yes) & X 16.5; median, 7; mode, 6; range, 1-61 \\
Practice-related grants (both research and program) past 5 years & \\
(20 of 21 reporting) (mean \#) & $16(76 \%)$ \\
School's PMI goals include research/practice integration (n/\% yes) & X 20, median, 10; mode, 8; range, 5-80 \\
Faculty engaged in practice (12 of 21 reporting) (mean\#) & $19(90 \%)$ \\
Practice addressed in appointment, promotion, tenure criteria & \\
(clinical track or practice integrated in tenure & \\
criteria; n/\% yes) &
\end{tabular}

NOTE. $\mathrm{N}=21$

Current practice activity covered a gamut of models, including contracts ( $\mathrm{n}=18,86$ percent), partnerships ( $\mathrm{n}=8,38$ percent), and practices for which the school was at full financial risk $(n=17,81$ percent). Several schools $(n=16,76$ percent $)$ reported a mixedpractice portfolio, which included ownership and operation of a variety of communityoriented practices, partnership arrangements, and/or contracts or joint appointments with service agencies. Eleven schools (52 percent) had formal faculty practice plans in place, and 12 (57 percent) identified in their applications that they held specific expertise in the business aspects of practice.

With regard to track records in supporting practice through research and program grant activity, 20 schools reported holding anywhere from 1 to 61 grants in the past 5 years, with an average of 16.5 each; the majority of these appeared related to support for educational or practice activities rather than for research, although some applications did 
not distinguish. Over three fourths of the schools identified at least one goal for their participation that was related to increasing or strengthening the integration of research and practice. Of the 12 schools that responded to the question about faculty in practice, an average of 20 faculty per school (median 10, mode 8) were currently practicing (range, 580) (proportion of total faculty unknown). Ninety percent $(n=19)$ of the schools either had a separate clinical track in place for practicing faculty or had developed special criteria for practice faculty to achieve tenure.

Each school was asked to identify and send to the institute an academic practice resource team (APRT) whose members could represent 3 perspectives essential for academic practice success: research/practice nursing faculty, health care business manager (or equivalent), and/or academic financial administrator. Although most APRTs showed some mix in perspectives, they also varied widely in faculty level and rank(junior or senior, tenured or clinical), faculty responsibilities (departmental administration, practice or research administration, practice/teaching), and levels and types of administrative personnel (practice managers, school business managers, health science center or university-level financial administrators). For nearly half of the schools $(n=9)$, the dean also attended at least a portion of the institute. Schools identified a broad set of goals for participating in the PMI, ranging from those aimed at attaining fiscal viability, building infrastructure, and structuring organization for practice, to those aimed at integrating research and education with practice and providing for appointment, promotion, and tenure criteria to support faculty engaged in scholarly practice pursuits. The schools' APRTs refined their goals by the end of the 5-day institute and submitted evaluations of goal achievement both quarterly and at the end of one year. In summary, the 21 participating schools came with a broad range of academic practice experience, expertise, and organizational commitment that undoubtedly helped shape their individual goal achievement.

\section{Major Learning and Evaluation Components}

\section{PENN MACY INITIATIVE}

The PMI had 5 major components: the application process itself (see previous section), an intensive summer Institute, follow-up consultation and support, a senior fellows exchange, and participation in evaluation (see Evaluation Methods section).

\section{Five-Day Summer Institute}

The content for the intensive 5-day institute was designed to address specific critical areas related to advancing successful academic practice initiatives. Although some changes were made to the year 2 program based on participant feedback and new developments in the field, the content areas were essentially the same for both institutes (Lang et al., 2002). Daily themes for each year are listed in Table 3. Institute faculty were professors, clinicians, administrators, staff, and board members from the University of Pennsylvania in year 1; in year 2, Senior Fellows (first-year participants) provided some of 
the content. Teaching-learning methods included lecture/discussion, use of audiovisual materials, breakout sessions for small group discussions, and opportunities for field visits.

\section{TABLE 3. Daily Themes for Each Institute}

\section{9}

Academic Practice: A Foundation for Research

Academic Practice: Outcomes and Models

Dancing the Dance: The Practice-Research Tango

Resources to Mount a Successful Initiative

Academic Nursing Practice in the 21st Century

\section{0}

Academic Practice: Building a Foundation for Research

Academic Practice: Exemplars, Outcomes, And Organizational

Infrastructure

Dancing the Dance: The Practice-Research Tango

Resources to Mount a Successful Initiative

Envisioning Academic Nursing Practice in the New Millenium

\section{Individualized Consultation and Networking Support}

Each school was offered up to 5 hours of consultation from the Penn Macy faculty, to be provided during and/or in the year after the institute. Schools were free to identify specific areas for which consultation was needed. Resource persons from or identified by the PMI faculty provided the consultation services that were delivered using a variety of methods including face-to-face, teleconferencing, and email. The topics chosen were concentrated in the areas of finance, organization, research, and clinical issues (see Lang et al., 2002). Of 105 hours of consultation available, 15 of the 21 schools asked for and used a total of 45 hours of consultation (average, 3 hours each for schools using the service). Only 3 schools used their full allotted quota of consultation resources.

To provide additional and continuing sources of information and opportunities for communication, a variety of electronic methods were developed: a Web site, listserv, discussion board, and monthly chat room. As new electronic media then in vogue (19992001), the listserv, discussion board, and chat room initially held out great promise for keeping Fellows connected. None proved, however, ideal for sharing ideas among Fellows. An e-mail listserv was developed to facilitate sharing among Fellows in a secure and confidential environment. The listserv was used effectively to broadcast announcements, but questions regarding academic practice issues seldom received more than cursory responses. By the Fall of year 2, monthly chat rooms, initiated early in year 1, were discontinued because of difficulty matching schedules across 3 time zones and participant discomfort with the technology. An alternative methodology, a Web-based discussion board mounted on the pennmacy.com site, was initiated but never used by 
Fellows after the first days. The Web site, pennmacy.com, continues to be an important information resource. It currently provides information about academic nursing practice; the PMI and its Fellows and participant schools; descriptions of the academic practices at the University of Pennsylvania School of Nursing; slide presentations from academic practice rounds; an integrated, searchable bibliography about academic practice; and a knowledge center including lists of common data elements being collected for practicebased research. Although the number of Web sessions is tracked routinely, the proportion of sessions used by Penn Macy Fellows is not known. Perhaps most effective, Fellows networked extensively during the Institute and followed-up directly with contacts. Some had peer Fellows visit their own schools for consultations or presentations. At midyear, nearly one third of the Fellows met during a national meeting to network, share, and plan their next steps.

\section{Senior Fellows Exchange}

Fellows returned to Penn 1 year after their summer institute $(2000,2001)$ for a Senior Fellows Exchange to discuss the lessons learned. Teams were invited to examine and share topics and issues of concern with all Penn Macy Fellows in an open forum. The following topical areas, based on submitted progress reports, were the foundation for formal presentations during the Senior Fellows Exchange: evolving academic practice models, increasing research integration into practice, and database issues in research and practice operations (1999); and survival and growth - diversification in academic nursing practice; faculty practice - recognition, promotion, and incentive compensation; and increasing research integration into practice (2000). Three schools chose not to participate in the Senior Fellows Exchange because of changes in their missions and/or operations.

\section{Evaluation Methods and Outcomes}

\section{METHODS}

The evaluation plan included 2 methods: participant daily and postconference feedback on the Institute, and quarterly and end-of-year self-reports on key indicators and school goal achievement. Each summer institute was designed specifically to respond to common needs identified in a review of participant schools' self-assessments and also to include areas that had been identified by the PMI faculty as essential to achieving an integrated tripartite mission (Lang et al., 2002). At the end of each day and the conclusion of the institute, using a standard rating tool, participants were asked to evaluate systematically the speakers, content, and teaching/learning methods. Space for written comments also was provided.

Before attending the institute, through the application process, and after their attendance, through progress reports, participant schools were responsible for self evaluating the degree to which they reached their academic practice goals. Quarterly and annually the teams were asked to assess their progress toward reaching their own selfdetermined goals as well as their achievements in several critical indicators: fiscal viability, 
planning and operations, educational integration, research integration, and organizational viability. Schools were given the option of producing quantitative or narrative reports. Based on the self-assessment, teams were offered assistance to reshape their plans and strategies.

\section{FINDINGS/OUTCOMES}

\section{Participant Feedback}

Individual participants were asked to evaluate the degree to which each of the objectives for the initiative was achieved during the 5-day institute (see combined ratings for years 1 and 2, Table 4). The opportunity to form peer relationships and to examine more closely the importance of academic nursing practice for the profession were the 2 most highly rated objectives. (Note: Other goals were expected to take the entire year to achieve). On a daily basis, participants were asked to rate speakers, content, and methods. In each year, all speakers, content, and methods were rated higher than average to excellent. Specific feedback was used each day during the institute to make modifications in format and content for subsequent sessions, and, at the end of the institute, to plan for the following year. Suggestions included more time for dialogue, networking, and small-group work; greater emphasis on balancing competing demands; content on models for partnerships and linkages with existing health systems; more content on health policy, business, and financial aspects, especially reimbursement; and facilitating faculty adoption of academic practice as a priority.

\section{TABLE 4. Overall Participant Evaluations of the Penn Macy Institute}

\begin{tabular}{llll}
\hline Number & \multicolumn{1}{c}{ Objective } & $\mathbf{1 9 9 9}$ & $\mathbf{2 0 0 0}$ \\
\hline 1 & $\begin{array}{l}\text { Describe the value of academic nursing practice to the further development } \\
\text { of the discipline of nursing for the 21st century. }\end{array}$ & 5.00 & 4.81 \\
2 & $\begin{array}{l}\text { Identify and assess institutional appropriateness of a range of methods for } \\
\text { integrating research, education, and practice in academic nursing. }\end{array}$ & 4.77 & 4.45 \\
3 & $\begin{array}{l}\text { Discuss entrepreneurial business strategies associated with achieving fiscally } \\
\text { viable nursing practice in an academic setting. }\end{array}$ & 4.73 & 4.38 \\
4 & $\begin{array}{l}\text { Assess barriers and challenges associated with institutionalizing academic } \\
\text { nursing practice in research-intensive universities and describe their potential } \\
\text { resolution. }\end{array}$ & 4.77 & 4.50 \\
\hline $\begin{array}{l}\text { Refine a 2-year plan, including milestones and critical indicators, for } \\
\text { individual schools' continuing evolution of academic practice. }\end{array}$ & 4.42 & 4.07 \\
\hline $\begin{array}{l}\text { Establish a network of peers in research-intensive universities for ongoing } \\
\text { collaboration and consultation. }\end{array}$ & 4.96 & 4.73 \\
\hline
\end{tabular}

NOTE. Ranking is high (5) to low (1). 
Participants listed what they intended to do as a result of the learning. Their responses cluster into the following major areas: research integration, organizational/structural changes, business, finance, information systems, and leadership/faculty awareness efforts. Overall, the following comments about the institute itself are representative:

- "This program focuses on both the theoretical strengths and pragmatic solutions for successful academic practice."

- "The networking opportunities were phenomenal."

- "I appreciated the honesty regarding successes and failures in academic nursing practice."

- "The content was compelling and made a strong case for the expansion of academic nursing practice."

\section{Self-Evaluation}

Although important for evaluating the impact of the initiative, the self-reports were also viewed as a significant source of data for the schools themselves to facilitate their own decision making and strategic action toward meeting goals. Thus, schools that were able to participate in the evaluation process arguably had more data at their fingertips for strategic planning. Every school (n $\ulcorner 21)$ submitted an end-of-year progress report; 7 schools submitted quarterly reports. Similar to the applications, the level of detail in the progress reports was variable.

Despite both the distinctive characteristics of each school and its goals, and the varying degree of detail in the reports, we were able to make overall summary assessments of each school's progress. We reviewed and assigned a level of progress (above expectations, as expected, minimal) in each of the critical indicators as well as for individualized goal achievement and progress overall. The critical indicators were (1) practice fiscal viability, (2) planning and operations, (3) educational integration, (4) research integration, and (5) organizational viability. Progress in achieving self-identified goals and objectives was expected for all participants. Although each school's annual progress report formed the basis of the summary assessment, we also took into account the developmental level and implementation stage of each school's academic practice in making our judgments. The seemingly small gains in programs were recognized and appreciated in relation to a school's stage of development. In fully operational and mature programs, progress was assessed more critically.

Over 80 percent of schools reported progress as expected or progress above expectations in planning and operations, and more than 75 percent of schools reported similar progress in organizational viability. Overall, there was minimal progress made in research integration. 


\section{Key Accomplishments}

We reviewed the evaluation data presented earlier and identified several key accomplishments exhibited by at least 1 participant school in the key areas.

In the area of practice fiscal viability, schools:

- Diversified their portfolios of academic nursing practices and settings;

- Added new sites to faculty practice plans;

- Conceptualized an innovative practice model.

In the area of planning and operations, schools:

- Implemented practice-based clinical information systems;

- Established benchmarks for service provision, patient satisfaction, and selected patient care outcomes;

- Tracked and reported financial and clinical indicators and compared with national benchmarks;

- Developed and implemented fiscally sound business plans;

- Aggressively negotiated contracts for covered lives and better managed care rates and secured new state grants;

- Negotiated for billing and other infrastructure support services.

As an example of education integration, schools implemented new courses incorporating knowledge derived from academic practice.

In the area of research integration, schools:

- Integrated funded research projects into practice settings;

- Paired clinicians with research faculty to enhance clinical research;

- Implemented a multidimensional model for clinical scholarship.

In the area of organizational viability, schools:

- Established new interdisciplinary relationships and partnerships and consulted among their newly developed PMI peers/fellows;

- Organized and reorganized faculty practice plans/councils;

- Reworked appointment, promotion, tenure criteria;

- Established organizational visibility and leadership for academic practice within the school structure.

Accomplishments outside the critical indicator areas also were noted. Schools:

- Developed a public domain Web site for advanced practice nursing reimbursement issues;

- Received new national awards for their practices;

- Established the brand name of Penn Macy synonymous with advancing leadership in academic nursing practice. 
Several schools showed significant initiative in implementing lessons learned whereas others appeared to have more difficulty. Thus, we considered whether there might be certain baseline and process characteristics that distinguished schools in terms of their readiness for progress.

\section{Key Indicators for Success}

To determine characteristics that distinguished applicant schools, we identified the 6 schools that showed an overall progress above expectation and the 3 schools that showed minimal progress in both critical indicator and goal achievement. Data from each of these schools then were scrutinized further to determine the presence of each of the 16 baseline or process characteristics believed to be important to successful movement in academic practice development. Characteristics deemed most important included having a place for practice on the school's organizational chart, having a critical mass of faculty in practice, and having clear and achievable goals (Table 5).

As depicted in Table 5, 7 of the 16 characteristics were shown by every school that progressed above expectations; however, no characteristics were shown by all of the schools with minimal progress. Only 1 of the schools with overall progress above expectation possessed all 16 characteristics, and none of the schools with minimal progress possessed more than 9 of the characteristics.

\section{TABLE 5. Key Indicators of Progress in Academic Practice Initiatives}

\begin{tabular}{lcc}
\hline \multicolumn{1}{c}{ Indicator } & $\begin{array}{c}\mathrm{N}(\%) \text { Most Successful } \\
(\mathrm{n}=6)\end{array}$ & $\begin{array}{c}\mathrm{N}(\%) \text { Less Successful } \\
(\mathrm{n}=3)\end{array}$ \\
\hline Practice integral to long range/strategic plan & $6(100 \%)$ & $2(67 \%)$ \\
Long history of practice & $6(100 \%)$ & $1(33 \%)$ \\
Practice integral to philosophy/mission/vision & $6(100 \%)$ & $2(67 \%)$ \\
Academic practice on organization chart & $5(83 \%)$ & $2(67 \%)$ \\
Critical mass of faculty in practice & $5(83 \%)$ & $1(33 \%)$ \\
Faculty practice plan & $4(67 \%)$ & $1(33 \%)$ \\
Academic practice involves financial risk taking & $2(33 \%)$ & $2(67 \%)$ \\
Portfolio is diverse & $3(50 \%)$ & $0(0 \%)$ \\
Practice addressed in appointment, promotion, tenure criteria & $6(100 \%)$ & $1(33 \%)$ \\
Team composition (richness) & $6(100 \%)$ & $0(0 \%)$ \\
PMI goals clear/achievable & $6(100 \%)$ & $2(67 \%)$ \\
Tripartite mission addressed in PMI goals & $5(83 \%)$ & $2(67 \%)$ \\
Leadership/administrative commitment shown & $5(83 \%)$ & $2(67 \%)$ \\
Quality application packet & $3(50 \%)$ & $0(0 \%)$ \\
r 2 h of consultation used & $4(67 \%)$ & $1(33 \%)$ \\
General readiness factor & $6(100 \%)$ & $0(0 \%)$ \\
& &
\end{tabular}

Several important observations can be made from these data. Structural characteristics, such as a clear place for practice in statements of mission, vision, philosophy, and long-range strategic plans, a history of faculty practice, and appointment/promotion and tenure criteria that address practice are important, but do not in 
and of themselves ensure successful achievement of academic practice goals. Likewise, preparing an exceptional application for the PMI, setting clear and achievable goals and strategies, and displaying an overall general readiness for mounting an initiative also are important but are insufficient alone. Not all of the schools rated above expectation had practice plans or diverse portfolios, were taking financial risk for their practices, had prepared a careful (the best) application, or took advantage of available consultation. Still, they were able to move their agendas forward on return to the home setting.

\section{Summary and Conclusions}

Twenty-one schools of nursing from research-intensive environments participated in an intensive initiative to enhance academic nursing practice. Each began the experience with a unique set of characteristics, experiences, contexts, and goals. By analyzing selfreported achievements from participating in the initiative over 1 year, we found that schools displayed a range of successes both in critical indicators for academic practice and in reaching their own goals. A critical review of these findings led us to conclude 3 major points:

- It would appear that key characteristics (Table 5) are important to academic practice progress. It is not having all of the critical factors in place but, rather, the unique, individualized mix that is important. Only 1 school that progressed above expectations possessed all 16 of the characteristics, and schools that progressed minimally showed some of them. The importance of a particular characteristic appears to be dependent contextually. That is, the history of the school, its location in a particular university and health environment, the commitment and vision of the dean and administration, the composition and mission of the faculty, strategic plans for the school, and access to external and internal resources point to characteristics that are important at a given point in time to successful movement in integrating the tripartite mission. Even schools with a long history of practice would do well to reassess their own indicators and characteristics periodically because circumstances, financing mechanisms, leadership, and missions change.

- Thus, a school's understanding of its own history, mission, and environment is essential. Schools that had clear goals and were ready to take advantage of the learnings afforded through the Initiative also appeared better able to take advantage of other opportunities for advancing their practice missions when they arose. Such schools displayed a critical readiness factor, and their teams were able to use the stimulation of participating in the Initiative to move swiftly toward reaching their goals.

- Research integration remains a very challenging goal to achieve in researchintensive environments. Although increasing research integration into practice was identified as a high priority across schools, it was the area that showed the least progress and, therefore, merits special attention. Despite discussion of a range of possibilities, no schools were able to mount successful solutions within a 1-year 
time frame. Where the practice and research functions of faculty are congruent rather than disparate, research integration is facilitated (Macnee, 1999). Where collaboration exists between clinical and research faculty, academic practice is more likely to result (Brown, 2001; Fagin, 2000; Jones \& Van Ort, 2001; Mayhew, 1994). Doctoral education that highlights this point (Burgener, 2001) is likely to make a difference in the future. Where schools serve large but similar populations over time, the opportunity to mount studies with adequate sample size and more rigorous designs is enhanced. When schools have been able to plan thoughtfully the research agenda along with the practice model (Naylor \& Buhler Wilkerson, 1999), including development of a minimum dataset (Zachariah \& Lundeen, 1997), they experience a greater likelihood of success for integration than when trying to retrofit the research onto the practice. The notion of establishing collaborative practice-based research networks (Grey \& Walker, 1998) is an idea that holds great promise for facilitating academic practice agendas.

Bridging the research-practice chasm and achieving stable financial support are, perhaps, the most formidable remaining barriers to achieving full integration of academic practice for nursing. These are not likely resolved without concerted attention and creative problem solving. These will become the major agenda for the remainder of the decade.

\section{References}

Brown, M. A. (2001). Academic faculty practice: Enrichment through synergism. Applied Nursing Research, 14, 56-61.

Burgener, S. C. (2001). Scholarship of practice for a practice profession. Journal of Professional Nursing, 17, 46-54.

Fagin, C. M. (2000). Executive leadership: Improving nursing practice, education and research. In C. M. Fagin (Ed.), Essays on nursing leadership, (pp. 61-75). New York: Springer.

Grey, M., Walker, P. H. (1998). Practice-based research networks for nursing. Nursing Outlook, 46, 125-129.

Jones, E. G., Van Ort, S. (2001). Facilitating scholarship among clinical faculty. Journal of Professional Nursing, 17, 141-146.

Lang, N. M., Evans, L. K., Swan, B. A. (2002). Penn Macy Initiative to Advance Academic Nursing Practice. Journal of Professional Nursing, 18, 63-69.

Macnee, C. L. (1999). Integrating teaching, research and practice in a nurse-managed clinic. Nurse Educator, 24, 25-28. 
Mayhew, P. A. (1994). Academic practice collaboration for nursing research. MEDSURG Nursing, 3, 230-231.

Naylor, M. D., Buhler-Wilkerson, K. (1999). Creating community-based care for the new millennium. Nursing Outlook, 47, 120-127.

Zachariah, R., Lundeen, S. P. (1997). Research and practice in an academic community nursing center. Image: Journal of Nursing Scholarship, 29, 255-260. 